\title{
Word Difficulty and Learning among Native Arabic Learners of EFL
}

\author{
Ahmed Masrai $^{1} \&$ James Milton $^{1}$ \\ ${ }^{1}$ Department of English Language and Literature, Swansea University, Swansea, UK \\ Correspondence: Ahmed Masrai, Department of English Language and Literature, Swansea University, Swansea, \\ SA2 8PP, UK. Tel: 44-742-914-0014. E-mail: a.m.masrai@swansea.ac.uk
}

Received: February 25, 2015 Accepted: April 2, 2015 Online Published: May 28, 2015

doi:10.5539/elt.v8n6p1 URL: http://dx.doi.org/10.5539/elt.v8n6p1

\begin{abstract}
This study investigates word difficulty and learning among learners of English as a foreign language (EFL) in Saudi Arabia. Difficulty factors examined in the study include repetition of words in learners' EFL textbooks, word length and parts of speech, and adds a further consideration which is underexplored in the literature; word translation equivalents in the learners' first language (L1). A total of 156 native Arabic participants were given a vocabulary test in which they had to identify whether a word was known to them and then to supply the meaning of the word in their L1 or L2. The findings showed a large effect of repetition on word learnability, accounting for $60 \%$ of the variance, followed by translation equivalence, which explained some $23 \%$ of the variance. Conversely, word length and the parts of speech element provided non-significant contributions to the overall model of learning. Thus, the results indicate a durable effect of repetition and a modest influence of L1 translation equivalent on the L2 vocabulary learning, regardless of the number of syllables in a word or the part of speech element.
\end{abstract}

Keywords: word difficulty, vocabulary learning, repetition, translation equivalence, learning model

\section{Introduction}

Words can vary in many respects. They can vary in the sounds and in the way they are formed. They also differ in the number of letters that make them up, how the sounds and letters are allowed to combine and how similar they are to a learner's native language. Words can differ in how they are allowed to change and make derived or inflected forms, such as the plural or past tense (Milton, 2009, p. 22). These features of words can either make L2 vocabulary learning easy or difficult.

Research has shown a great many factors that can influence L2 vocabulary acquisition. Factors such as frequency (Chen \& Truscott, 2010; Laufer \& Rozovski-Roitblat, 2011; Milton, 2009; Rott, 1999; Webb, 2007), length (Culligan, 2008), abstractness (Higa, 1965), cognateness (Tonzar, Lotto, \& Job, 2009), part of speech (Glanzer, 1962, cited in Rogers, 1969), semantic relatedness of the words in teaching sets (Erten \& Tekin, 2008; Tinkham, 1993, 1997; Waring, 1997), presence of music and visual aids (De Groot, 2006), inflectional complexity, derivational complexity, polysemy (Laufer, 1997) and L1 translation equivalent (Jiang, 2002, 2004; Matikainen, 2011) were found to have degrees of impact on L2 vocabulary learning. Nevertheless, most of the word difficulty factors mentioned above have been studied individually, looking at the relationship between word difficulty and only one variable at a time.

Very few EFL studies, however, have looked at word difficulty and learning incorporating more than one variable at a time (see Alsaif \& Milton, 2012; Milton \& Daller, 2007; Milton; 2009; Willis \& Ohashi, 2012). Although those studies provide insights into what might be the best predictor for L2 vocabulary learning, there still remain other factors, such as word translation equivalence in learners' L1, which might have a significant influence on L2 vocabulary uptake, have not been involved in explorations of any word-difficulty model. The present study, therefore, investigates the relative contribution of word frequency (repetition), word length, part of speech, and L1 translation equivalence to L2 vocabulary learning in one experimental setting. It is presumed that, in addition to frequency, word translation equivalence will contribute significantly to the overall model of L2 vocabulary learning, particularly in the early stages of L2 acquisition.

Concerning the latter variable, one of the main areas of focus in psycholinguistics research on the development of L2 knowledge has been the availability of L1 translation equivalence during L2 processing (De Bot \& Kroll, 2010). Although this line of psycholinguistics work had mainly shed more light on the speed and direction of 
translation, such as by using event-related brain potentials (ERPs) (Van Hell \& Kroll, 2013), the research generally proposes that L2 words with translation equivalents in learners' L1 might have a facilitative effect on L2 vocabulary acquisition. The efficacy of L1 translation equivalence will become clearer with beginner and low-level L2 learners. Kroll and Curley (1988) and Chen and Leung (1989) suggest that in the earlier stages of L2 acquisition and development, there is indeed lexical mediation, whereby L1 translation equivalents are activated to enable access to concepts. This idea needs to be further explored from a language teaching perspective to establish whether words with non-direct translation equivalents create difficulty for L2 learners and also to find the level of contribution of direct translation equivalence on L2 vocabulary acquisition.

The succeeding part of this section reviews the studies that have operationalised multiple factors in one general model to examine the relationship between word difficulty and learning.

Milton and Daller (2007) and Milton (2009) have used participants from British learners of French as a foreign language to explore the relationship between word difficulty and frequency (lemmatised frequency list from Baudot's 1992 vocabulary list), cognateness (number of letters common to L1 and L2 words) and word length (number of syllables in the L2 words). Findings from Milton and Daller's work, represented in a multiple linear regression model, showed that the only statistically significant variable was word frequency. The other variables were excluded from the model because their contributions were not significant; word frequency was found to explain about $30 \%$ of the variance. Findings from these two studies confirm that frequency does have a measurable impact on vocabulary learning. However, Milton (2009) attributes the insignificant effect of word length and cognateness on vocabulary learning to several reasons. One is that the systems used for assessing word difficulty featured in the study are not suitable to predict the qualities of difficulty, and that different forms of testing might produce diverse results. Another reason is that the target language in the study may have affected the results. As French and English have many words that are cognate, the causal effect of cognateness on vocabulary learning was not clear (Milton, 2009).

In another study that attempted to find answers similar to the questions addressed by Milton and Daller (2007), Willis and Ohashi (2012) investigated the relationship between word difficulty and the same variables reported by Milton and Daller (2007). However, Willis and Ohashi (2012) used participants from an L1 Japanese background. They also used part of the vocabulary size test (Nation \& Beglar, 2007) to measure the participants' vocabulary knowledge. Results from Willis and Ohashi's study show that cognateness, frequency and word length (in phonemes) best predict word difficulty for Japanese learners of English as a second language (ESL) in terms of learning and retaining L2 words over time. Yet the most influential factor in the learning model was cognateness. It was found to account for the largest contribution to difficulty, followed by frequency and then word length in phonemes.

One more study that looked at the relationship between word difficulty and more than one variable at the same time was Alsaif and Milton (2012). Their study investigated three difficulty factors: word length, repetition and concreteness, using participants whose L1 was Arabic. Findings from this study suggest that the three variables combined together can explain $63.8 \%$ of the variance in the learners' scores. Word length was found to make the greatest contribution to vocabulary learning; accounting for about $36 \%$ of variance per se. Word length was followed by concreteness and frequency according to the effect they have on the overall results in the learning model.

This later study is important to our research for two reasons: one is that two of the variables, namely word length and repetition, will be investigated in the current study; second, participants in the current study are from the same L1 (Arabic) background. However, different from the study conducted by Alsaif and Milton (2012), the current study used participants from one school level (final year in high school) for two main reasons. One was to control for the potential to include participants who may not have encountered any of the tested words. The other was to have informants who had received the same number of instruction hours and be in the same age group.

Disappointingly, learners in government schools in Saudi Arabia were found to have very little L2 vocabularies when they leave high school. Studies have attempted to investigate EFL vocabulary size, e.g., Al-Hazemi (1993), Al-Bogami (1995) and Alsaif (2011), who all confirm that students graduating from high school were reported to know only about 1000 words. This very limited lexicon was found to be reflected in learners' achievements at undergraduate level. Masrai and Milton (2012), for instance, investigated the vocabulary of university level students majoring in the English language in Saudi Arabia. Their findings suggest that the students' vocabulary size was about 2000 to 3000 words after one year of university study and around 5000 words nearer graduation. These figures thus emphasise that Saudi university learners' level is, on average, some way short of that 
associated with complete fluency in EFL. There could be many reasons that lie behind the issue of the low vocabulary uptake by Arab EFL learners.

However, what makes a word either difficult or easy to learn is the scope of the current study. This study therefore attempts to find answers to the following research questions:

1) What combination of variables (word length, repetition, part of speech and word translation equivalence) best predicts the difficulty of $\mathrm{L} 2$ vocabulary learning?

2) What is the proportion or contribution of each of the factors?

\section{Method}

\subsection{Participants}

The 156 participants who were selected to take part in the current study were final-year students at high school in the Saudi Arabian education system. At the time of the data collection, the participants should have studied English as a compulsory subject for about seven years, having therefore received, on average, 832 hours of EFL classroom instruction. The participants' mean age was 18 .

\subsection{Data Collection}

Data for this study were collected in the second semester of the school year 2012/2013 in the Saudi education system. All the testing procedures were administered during the normal school classes by arrangement with the relevant authorities. As the intended participants in this study were from two different schools, data were collected over two days; one day for data collection from each school. Noteworthy is that all government schools in Saudi Arabia follow the same EFL syllabus provided by the Ministry of Education.

\subsection{Target Items and Measurement Instruments}

The target items were 30 English words taken from textbooks to which learners are exposed in the EFL programme in Saudi schools. Of these, one -brunch- was excluded because of complications regarding assessing compound and blend items. The remaining 29 test items were assigned to two categories: the first encompassed 15 items that have a direct translation equivalent in the participants' L1; the second category included 14 items which do not have a direct translation equivalent in the learners' L1. Before placing words into their appropriate categories, they were checked for their frequency in the lemmatised frequency list created by Kilgariff (2006), part of speech, length (number of syllables), frequency of occurrence across the learners' textbooks (repetition) and translation equivalence in the learners' L1. The authors considered the production of two equal groups of words (with vs. without translation equivalent) in terms of the elements mentioned above to be as representative a sample as possible.

To examine the frequency of occurrence of the target items in the learners' textbooks, a text file of teaching materials combining 22 pupils' books and workbooks was processed through the RANGE program (Heatley, Nation, \& Coxhead, 2002). The program can provide the number of tokens, types and families of all the words in the text file. It can also provide the frequency (number of occurrences) of each word across the learners' textbooks. The latter is needed in this study to calculate the repetition of the words intended for analysis. The analysis shows that the amount of vocabulary presented in students' textbooks is about 218,883 tokens, 8197 types and 3748 word families. Surprisingly, only around half of the most frequent 5000 words, including 1690 from the most frequent 2000 level, are presented in these materials.

The measurement used in this study was a vocabulary knowledge test comprising the 29 words discussed above. The test was devised in a yes/no format, by which a learner should identify whether he knows a word or not. Yes/no tests are documented in the literature of vocabulary testing as valid and reliable measures (e.g., Meara \& Milton, 2003; Mochida \& Harrington, 2006). Thus using this type of testing with Informants in the current study is believed useful for one main reason. The participants are low-level EFL learners, therefore, they might be able to recognise a given word and have a partial knowledge of it but would not be able to use it productively. Nonetheless, an extra measure was taken into consideration, where informants had to provide L1 (Arabic) or L2 (English) meaning of the target word to elicit more reliable data (see a copy of the test in appendix A).

\subsection{Procedures}

Test administration was carried out during the regular class hours and was not time limited. However, it was devised not to exceed 15-20 minutes to complete. Before performing the task, participants were given clear instructions about the nature of the test. Next, they were asked to check the words they know corresponding to their part of speech (part of speech was provided next to each tested word) and to provide the L1 or L2 meaning. The instructions were in both English and learners' L1. Since data were collected from two different schools, 
volunteer teachers from each school administered the test after they had received detailed instructions from the first author.

After the raw data were collected, they were marked manually to calculate the final score for each participant. The scoring system is straightforward; each checked word with the acceptable meaning weighs one point. As the words fell into two different categories (with and without L1 direct translation equivalence), the score for each participant in each category was recorded. Finally, the total score for all the participants for each word was also logged.

\subsection{Data Analysis}

After data had been marked and the responses of the 156 test-takers had been calculated, the data were processed using Statistical Package for the Social Sciences (SPSS) software (version 20). The data sheet involved five variables, one dependent variable and four independent variables. Inclusion of various factors corresponding to L2 vocabulary learning difficulties can help elucidate what could be a good vocabulary learning predictor. However, the data reported here were analysed through the participants' responses to find out what kind of word aspects might make some words learned better than others. In other words, what variable or variables best predict L2 vocabulary learning?

To study the effect of the difficulty factors mentioned earlier and also the inter-relationship between those factors, the following information was considered for each tested word:

1) The number of students who identified the word as known.

2) The number of occurrences of each tested word in the students' textbooks.

3) The word translation type (equivalent and non-equivalent).

4) The number of syllables in each word (word length).

5) The part of speech (e.g., verb, noun, adjective or adverb).

\section{Results}

\subsection{Word Difficulty and Potential Learnability}

Correlation coefficient analysis was performed to explore the relationship between word difficulty and the potential learnability and the predictor variables. Results reported in Table 1, summarised in Table 3 for further clarification, show Pearson's correlations between learners' responses to target words and four predictor variables: syllables (word length), the part of speech, word translation equivalence, and repetition. Interestingly, the variable that correlates most strongly with word difficulty is word repetition across learners' textbooks $(r=$ $0.772)$, followed by word translation equivalent type $(r=0.474)$. Both of these correlations are positive and significant $(p<0.01)$, indicating that it is generally easier to uptake words which are frequently encountered during the course of learning and have a direct translation equivalent in learners' L1 mental lexicons.

Figures reported in Table 1 also show a negative correlation between vocabulary learning and word length ( $r=$ -0.357). Although this correlation is weak, to a lesser extent it suggests that it is harder to learn longer words when compared to shorter ones. Parts of speech, according to the correlation analysis, do not seem to have a strong effect on L2 vocabulary learning $(r=0.140)$. To further explore the influence of these variables on vocabulary learning, a multiple linear regression analysis was performed. The results are presented in the following section.

Table 1. Correlations between word learnability and predictor variables (Pearson)

\begin{tabular}{llllll}
\hline & Response & Part of speech & Syllables & TE & Repetition \\
\hline Response & - & .140 & -.357 & $.474^{* *}$ & $.772^{* *}$ \\
Part of speech & - & - & -.169 & -.056 & .224 \\
Syllables & - & - & - & -.131 & -.324 \\
TE & - & - & - & - & .261 \\
Repetition & - & - & - & - & - \\
\hline
\end{tabular}

Note. 29 for all inter-correlations with the students' responses (Response), TE (Translation Equivalence).

**. Correlation is significant at the 0.01 level (2-tailed). 


\subsection{A Model of L2 Vocabulary Learning}

To find out the scale of effect of the variables mentioned above on vocabulary learning and also the inter-relationship between the variables, the data were analysed using stepwise multiple linear regressions. Table 2 , however, shows the best multiple linear regression model, which was comprised of two statistically significant predictors: repetition and word translation equivalence. The model as a whole is found to be significant $(F=$ 27.063, $p<0.001$ ), suggesting that both word repetition and word translation equivalence combined contribute considerably to the degree of learnability of a word, at least as far as concerns the sample group in this study.

Generally, the model accounts for almost $67.6 \%$ (Multiple $R^{2}=0.676$ ) of the variance. The word length and the part of speech factors were dropped from the model because their overall contribution to vocabulary uptake was found to be not significant. Surprisingly, it seems that word length makes a weak impact on word learning, accounting for some $13 \%$ of variance. Interestingly, repetition appears to make the greatest contribution to vocabulary learning, accounting for nearly $60 \%$ of the variance per se. This suggests that words which are encountered very frequently in the learners' textbooks are learned much better than words which are not.

Repetition was followed by the word equivalence type in the stepwise regression model. According to the model, words that do not have direct translation equivalence in the learners' L1 are harder to learn than words with one, considering that both types of words are of very similar frequency, length and part of speech. The contribution of the word translation type to the model accounts for about $23 \%$ of variance.

Table 2. Best multiple linear regression model found using the stepwise procedures

\begin{tabular}{lllll}
\hline Model & $R$ & $R^{2}$ & Adjusted $R^{2}$ & $S E$ of estimate \\
\hline 1 & $.772^{\mathrm{a}}$ & .596 & .581 & 23.92229 \\
2 & $.822^{\mathrm{b}}$ & .676 & .651 & 21.85384 \\
\hline
\end{tabular}

(a) Predictors: (Constant), repetition; (b) Predictors: (Constant), repetition, equivalence.

Table 3. Summary of correlations $(r)$ and coefficient of determination $\left(r^{2}\right)$ between word learnability and the predictor variables

\begin{tabular}{llll}
\hline Word learnability & $r$ & $r^{2}$ & $p$ value \\
\hline Repetition & $0.772^{* *}$ & 0.581 & $0.000^{* * *}$ \\
Equivalence & $0.474^{* *}$ & 0.224 & $0.009^{* *}$ \\
Part of speech & 0.140 & 0.020 & 0.469 \\
Syllables & -0.357 & 0.128 & 0.057 \\
\hline
\end{tabular}

**. Correlation is significant at the 0.01 level (2-tailed).

$P$ value: sig. $* * * 0.001, * *<0.01$.

\section{Discussion}

This study aimed to examine the relationship between some word difficulty factors and EFL vocabulary uptake by addressing these questions: (a) what combination of variables (word length, repetition, parts of speech and word translation equivalence) best predicts the difficulty of L2 vocabulary learning? And (b) what is the percentage of contribution of each of the factors?

The findings suggest that a model of a considerable effect for repetition and word translation equivalent can best predict vocabulary learning for Arabic-speaking learners of English. Word repetition across learners' textbooks was found to make the greatest contribution to the ease of learning and thus the best predictor of vocabulary uptake. It confirms that words which are encountered 10 times or more are better learned than words that fall into the opposite end of the spectrum. This idea is supported theoretically by other research (e.g., Gairns \& Redman, 1986; Saragi, Nation, \& Meister, 1978; Webb, 2007).

Nation (2001), on the other hand, claims that, depending on the vocabulary learning burden, some individual words may require 20 repetitions or more before they are transferred into the long-term mental lexicon and used for production. Nevertheless, it cannot always be assumed that all the frequently repeated words are eventually 
learned. For example, the word 'aunt' appearing in the test used in the current study is repeated 39 times in the students' textbook, yet it was found to have been learned by only six students out of the total number of 156 participants. In contrast, the word 'cable' is repeated only four times but was learned by 20 students.

The example above illustrates that there are words in the language that do not follow certain patterns and the relationship between frequency of occurrence (repetition) and vocabulary uptake is not always linear. It is likely to see some words that are learned even when they have occurred only a handful of times, whereas others remain stubbornly unlearned even when they are repeated many times during the language acquisition process. This kind of evidence suggests that vocabulary learning is a product of several variables of difficulty.

In the vocabulary learning model, produced by regression analysis in this study, word translation equivalence accounts for nearly $23 \%$ of variance, representing the second most important predictable variable for enhancing vocabulary learning in the model. The model suggests that words with a direct translation equivalent are best learned than those which do not. According to Milton (2009), target words in a foreign language that have an existing direct translation equivalent in a learner's native language, might be learned much easier than those that require creation of new concepts of knowledge. This finding supports Milton's assumption and suggests that words with a direct translation equivalent in a learner's native language can play an influential role in foreign language vocabulary acquisition.

Let us look at the example of 'aunt' and 'cable' again. It was mentioned that the word aunt is repeated 39 times across learners' textbooks yet found to be learned by only six learners out of the 156 who participated in this study, while the word cable is repeated four times but learned by 20 learners. In fact, the word aunt does not have a direct word translation equivalent in Arabic whereas the word cable has. This suggests that the existence of a direct meaning for L2 lexical items in the learners' L1 mental lexicon might explain why the word cable was learned by more learners than the word aunt, although the former is repeated much less. This idea does not contradict the importance of word repetition, as it is widely confirmed by a body of research, but points to other significant factors involved in the process of vocabulary learning such as direct word translation equivalence.

Even though the idea of direct word translation equivalence is not empirically supported, the findings here could establish a line of research for future investigation of this word acquisition issue by recruiting participants from a variety of L1 backgrounds which are not cognate with the target language.

The third and fourth variables included in the multiple regression analysis were word length and part of speech. These two variables were excluded from the stepwise regression model as they did not reveal a significant contribution to the overall model. It is noteworthy that word length, although insignificant, can be explained to an extent as word difficulty $(r=-0.357)$. This finding does not appear to be consistent with the finding reported in the study conducted by Alsaif and Milton (2012), which suggests some level of correlation $(r=-0.599)$ between word length and word difficulty. This can probably be attributed to two factors: (a) the average length of words tested in this study, as they appear shorter than words tested in Alsaif and Milton (2012); and, (b) the participants who took part in the current study were all final year high school students whereas test-takers in Alsaif and Milton's study ranged from year six to the final high school year.

It could be argued here that shorter words (three syllables or less) will not significantly hinder L2 vocabulary learning as much as longer words might do. Also, as the learners' level in the L2 increases, their morphological awareness is most likely increased too (Koda, 2000). This can explain, to an extent, why word length does not contribute significantly to the model of L2 vocabulary learning in the current study. Moreover, there seems to be no agreement among researchers about the effects of word length as a difficulty factor on learning. Laufer (1997), for example, classified word length as a factor with no clear effect on vocabulary learning in her study.

The part of speech or word class appeared not to have any effect on overall vocabulary acquisition in the multiple regression model, as far as concerned participants in this study. In a considerable body of research, nouns are found to be much easier to uptake than any other word class (e.g., Horst \& Meara, 1999; Nation, 2000). However, it is worth mentioning that the words tested here were all very frequently used words in English and were not tested in high quantity, which might explain the insignificant contribution of the word length to the model produced. Word frequency according to some scholars (e.g., Milton, 2009; Nation, 1990, 2000) can play an undeniable role in vocabulary learning, regardless of word type. For example, if an adjective is encountered more frequently than a noun, the former might potentially be learnt and used less than the encountered noun. Therefore, the frequency of a word's occurrence generally impacts vocabulary uptake to a great degree.

To sum up, findings reported in this study show that an additive model of effects for word repetition (frequency of occurrence) in learners' textbooks and direct translation equivalence between words in the target and native languages can best predict the ease for Arabic EFL learners for learning and retaining L2 vocabulary over time. 
The major contributor to vocabulary acquisition was repetition, followed by the existence of a direct word translation equivalent and then, to a lesser extent, word length, although the latter was statistically insignificant. These factors combined appear to have an effective impact on the degree of word learnability.

\section{Limitations and Suggestions for Future Research}

It must be acknowledged, however, that this particular study has some limitations. Despite the fact that findings reported here go some way to help explain the way individual words work in the learning process, it cannot be emphasised too strongly since these results are drawn from a small number of words $(n=29)$. The words were almost all in the base form, making words shorter to accurately model the effect of word length on vocabulary learning. Another word of caution is that the model of vocabulary acquisition found in this particular study is that of vocabulary acquisition by native Arabic learners of English. Models are likely to be different when different pairs of languages are used (Green \& Meara, 1995).

Further research, taking into account the limitations of this study, is warranted to refine our understanding of the effect of translation equivalence, repetition, length and parts of speech on L2 vocabulary learning. Thus, replication of this study is suggested using a greater quantity of words and in longer forms, i.e., including a diversity of affixes. Further, recruiting participants representing a diversity of L1 backgrounds would support generalising the findings reported in this study.

However, the findings of this study have a number of implications for teaching and learning vocabulary. Firstly, they suggest that words with a direct translation equivalent should be introduced in larger quantities at the initial stages of learning, as they are found to be relatively easy to learn. Consequently, this could inspire learners to learn more words and might reinforce more successful autonomous learning. Additionally, there are implications for deliberate recycling (repetition) of vocabularies in learners' textbooks. Repetition was found to explain nearly $60 \%$ of variance in the vocabulary learning difficulty model. Therefore, language teachers should pay attention to recycling words that are stubbornly learned, such as words with none direct translation equivalents, in the course of the learning process.

\section{Conclusions}

The present study showed native Arabic EFL learners acquiring words more readily that frequently recur in the textbooks and have direct L1 translation equivalence. The results of this study thus emphasise the importance and efficacy of frequency of occurrence and mapping new L2 words to the existing L1 knowledge base in vocabulary learning. It was found that word repetition and direct word translation equivalents combined explained nearly $68 \%$ of variance in a word difficulty model of learning. Word repetition, which is theoretically supported by a line of research, was found to be the greatest contributor to English vocabulary uptake by EFL learners in Saudi public schools. Findings relevant to word repetition in this study conform to findings from Alsaif and Milton (2012). Therefore, it might reasonably be assumed that the focus in teaching vocabulary aimed at Arabic learners of English will clearly be on providing sufficient levels of repetition for each encountered word during a course of learning.

Interestingly, the existence of a direct translation equivalent between words in learners' L1 (Arabic) and the target language (English) was also revealed to be a statistically significant predictor of L2 vocabulary learning. This implies that L2 words which have a direct translation equivalent in the learners' L1 mental lexicon are more easily learned by mapping these words to the existing L1 lexical knowledge. In contrast, words which do not have this kind of relationship might need mapping to new concepts which might not be possible in the early stages of learning (Jiang, 2004). Accordingly, uptake of these types of words may perhaps not occur unless considerable attention by language teachers is paid to them. Providing an abundance of authentic examples, including L2 words without translation equivalents in the L1 that link those words to new L2 concepts should enhance their acquisition.

Finally, parts of speech and word length were found to be insignificant in their contribution to L2 vocabulary learning in the model formed using multiple regression analysis, although word length can be seen to have a relatively modest influence on vocabulary learning. The findings of this study appear to conform to those found in the study by Willis and Ohashi (2012), although, on the other hand, they contradict findings from the study by Alsaif and Milton (2012). The slight contribution of word length to L2 vocabulary acquisition found in this study suggests that the effect of length remains inconsistent in the literature (Laufer, 1997; Milton, 2009). Even though the findings of this study should be interpreted with care, given the limited number of target items per L1 translation condition, it was clear that repetition of newly introduced vocabulary and presentation of words with direct translation equivalents in the learners' textbooks more readily allowed learners to acquire L2 vocabulary. 


\section{References}

Al-Bogami, A. (1995). Teaching English vocabulary to EFL male students at intermediate and secondary public schools in Riyadh (Unpublished master's dissertation). King Saud University, Riyadh.

Al-Hazemi, H. (1993). Low level EFL vocabulary tests for Arabic speakers (Unpublished doctoral dissertation). University of Wales, Swansea.

Alsaif, A. (2011). Investigating vocabulary input and explaining vocabulary uptake among EFL learners in Saudi Arabia (Unpublished doctoral dissertation). Swansea University, Swansea.

Alsaif, A., \& Milton, J. (2012). Vocabulary input from school textbooks as a potential contributor to the small vocabulary uptake gained by English as a foreign language learners in Saudi Arabia. The Language Learning Journal, 40(1), 21-33. http://dx.doi.org/10.1080/09571736.2012.658221

Baudot, J. (1992). Fréquences d'utilisation des mots en français écrit contemporain. Montréal: Les Presses de l'Université de Montréal.

Chen, C., \& Truscott, J. (2010). The effects of repetition and L1 lexicalization on incidental vocabulary acquisition. Applied Linguistics, 31(5), 693-713. http://dx.doi.org/10.1093/applin/amq031

Chen, H.-C., \& Leung, Y.-S. (1989). Patterns of lexical processing in a non-native language. Journal of Experimental Psychology: Learning, Memory, \& Cognition, 15(2), 316-325.

Culligan, B. (2008). Estimating word difficulty using yes/no tests in an IRT framework and its application for pedigogical objectives (Doctoral dissertation). Temple University, Japan.

De Bot, K., \& Kroll, J. F. (2010). Psycholinguistics. In N. Schmitt (Ed.), An introduction to applied linguistics (2nd ed., pp. 124-142). New York: Routledge.

De Groot, A. M. B. (2006). Effects of stimulus characteristics and background music on foreign language vocabulary learning and forgetting. Language Learning, 56(3), 463-506. http://dx.doi.org/10.1111/j.1467-9922.2006.00374.x

Erten, I. H., \& Tekin, M. (2008). Effects on vocabulary acquisition of presenting new words in semantic sets versus semantically unrelated sets. System, 36(3), 407-422. http://dx.doi.org/10.1016/j.system.2008.02.005

Gairns, R., \& Redman, S. (1986). Working with words: A guide to teaching and learning vocabulary. Cambridge: Cambridge University Press.

Glanzer, M. (1962). Grammatical category: A rote learning and word association analysis. Journal of Verbal Learning and Verbal Behavior, 1(1), 31-41. http://dx.doi.org/10.1016/S0022-5371(62)80016-4

Green, D., \& Meara, P. (1995). CALL and vocabulary teaching. Computer Assisted Language Learning, 8(2), 91-101.

Heatley, A., Nation, I. S. P., \& Coxhead, A. (2002). Range [Computer software]. Retrieved from http://www.victoria.ac.nz/lals/staff/paul-nation/nation.aspx

Higa, M. (1965). The psycholinguistic concept of "difficulty" and the teaching of foreign language vocabulary. Language Learning, 15(3-4), 167-179. http://dx.doi.org/10.1111/j.1467-1770.1965.tb00799.x

Horst, M., \& Meara, P. (1999). Test of a model for predicting second language lexical growth through reading. Canadian Modern Language Review, 56(2), 309-330. http://dx.doi.org/10.3138/cmlr.56.2.308

Jiang, N. (2002). Form-meaning mapping in vocabulary acquisition in a second language. Studies in Second Language Acquisition, 24(4), 617-637. http://dx.doi.org/10.1017/S0272263102004047

Jiang, N. (2004). Semantic transfer and its implications for vocabulary teaching in a second language. The Modern Language Journal, 88(3), 416-432. http://dx.doi.org/10.1111/j.0026-7902.2004.00238.x

Kilgarriff, A. (2006). BNC database and word frequency lists. Retrieved October 11, 2011, from http://www.kilgarriff.co.uk/bnc-readme.html-lemmatised

Koda, K. (2000). Cross-linguistic variations in L2 morphological awareness. Applied Psycholinguistics, 21(3), 297-320.

Kroll, J. F., \& Curley, J. (1988). Lexical memory in novice bilinguals: The role of concepts in retrieving second language words. In M. Gruneberg, P. Morris, \& R. Sykes (Eds.), Practical aspects of memory (pp. 389-395). London: Wiley.

Laufer, B. (1997). What's in a word that makes it hard or easy? Intralexical factors affecting the difficulty of 
vocabulary acquisition. In M. McCarthy, \& N. Schmitt (Eds.), Vocabulary description, acquisition and pedagogy (pp. 140-155). Cambridge: Cambridge University Press,.

Laufer, B., \& Rozovski-Roitblat, B. (2011). Incidental vocabulary acquisition: The effects of task type, word occurrence and their combination. Language Teaching Research, 15(4), 391-411. http://dx.doi.org/10.1177/1362168811412019

Masrai, A., \& Milton, J. (2012). The vocabulary knowledge of university students in Saudi Arabia. TESOL Arabia Perspectives, 19(3), 13-20.

Matikainen, T. J. (2011). Semantic representation of L2 lexicon in Japanese university students (Doctoral dissertation). Temple University, Japan.

Meara, P., \& Milton, J. (2003). X_Lex, The Swansea Levels Test. Newbury: Express.

Milton, J. (2009). Measuring Second Language Vocabulary Acquistion. Bristol: Multilinguial Matters.

Milton, J., \& Daller, H. (2007). The interface between theory and learning in vocabulary acquistion. Paper presented at the EUROSLA, Newcastle upon Tyne, UK.

Mochida, K., \& Harrington, M. (2006). The yes/no test as a measure of receptive vocabulary knowledge. Language Testing, 23(1), 73-98. http://dx.doi.org/10.1191/02655322061t321oa

Nation, P. (1990). Teaching and learning vocabulary. New York: Heinle and Heinle Publishers.

Nation, P. (2001). Learning vocabulary in another language. Cambridge: Cambridge University Press.

Nation, P., \& Beglar, D. (2007). A vocabulary size test. The Language Teacher, 31(7), 9-12.

Rodgers, S. (1969). Measuring vocabulary difficulty: An analysis of item variables in learning Russian-English vocabulary pairs. International Review of Applied Linguistics in Language Teaching, 7, 327-343. http://dx.doi.org/10.1515/iral.1969.7.4.327

Rott, S. (1999). The effect of exposure frequency on intermediate language learners' incidental vocabulary acquisition and retention through reading. Studies in Second Language Acquisition, 21(4), 589-619.

Saragi, T., Nation, I. S. P., \& Meister, G. F. (1978). Vocabulary learning and reading. System, 6(2), 72-78.

Tinkham, T. (1993). The effect of semantic clustering on the learning of second language vocabulary. System, 21(3), 371-380. http://dx.doi.org/10.1016/0346-251X(93)90027-E

Tinkham, T. (1997). The effects of semantic and thematic clustering on the learning of second language vocabulary. Second Language Research, 13(2), 138-163. http://dx.doi.org/10.1191/026765897672376469

Tonzar, C., Lotto, L., \& Job, R. (2009). L2 vocabulary acquisition in children: Effects of learning method and cognate status. Language Learning, 59(3), 623-646. http://dx.doi.org/10.1111/j.1467-9922.2009.00519.x

Van Hell, J. G., \& Kroll, J. F. (2013). Using electrophysiological measures to track the mapping of words to concepts in the bilingual brain: A focus on translation. In J. Altarriba, \& L. Isurin (Eds.), Memory, language, and bilingualism: Theoretical and applied approaches (pp. 126-160). New York: Cambridge University Press.

Waring, R. (1997). A comparison of the receptive and productive vocabulary sizes of some second language learners. Immaculata, 1, 53-68.

Webb, S. (2007). The Effects of Repetition on Vocabulary Knowledge. Applied Linguistics, 28(1), 46-65. http://dx.doi.org/10.1093/applin/aml048

Willis, M., \& Ohashi, Y. (2012). A model of L2 vocabulary learning and retention. The Language Learning Journal, 40(1), 125-137. http://dx.doi.org/10.1080/09571736.2012.658232

\section{Appendix A}

Test of English Word Difficulty

Name (Code):

Please tick $(\sqrt{ })$ the word you know from the following in the list and provide its meaning in Arabic or/and English. Please consider the part of speech provided when identifying the word as known or not (v, n, adj, prep). For example: 
كتاب $\sqrt{ }$ book

فضلا ضع علامة (ل) امام الكلمة التي تعرفها من القائمة ادناه مع كتابة معنى الكلمة بالعربية او الانجليزية او الاثنتين معأ. يجب مر اعاة نوع الكابل الكلمة

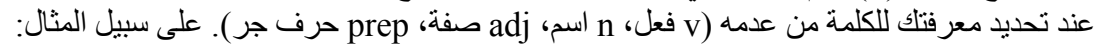
book $\sqrt{ }$

\begin{tabular}{|c|c|c|c|}
\hline & الكلمة - Word & Part of speech & المعنى - Meaning \\
\hline 1 & go & $\mathrm{V}$ & \\
\hline 2 & fish & $\mathrm{n}$ & \\
\hline 3 & travel & $\mathrm{V}$ & \\
\hline 4 & test & $\mathrm{v}$ & \\
\hline 5 & shirt & $\mathrm{n}$ & \\
\hline 6 & salt & $\mathrm{n}$ & \\
\hline 7 & reception & $\mathrm{n}$ & \\
\hline 8 & cable & $\mathrm{n}$ & \\
\hline 9 & patient & adj & \\
\hline 10 & customer & $\mathrm{n}$ & \\
\hline 11 & crazy & $\mathrm{n}$ & \\
\hline 12 & handle & $\mathrm{n}$ & \\
\hline 13 & signature & $\mathrm{n}$ & \\
\hline 14 & fridge & $\mathrm{n}$ & \\
\hline 15 & instructor & $\mathrm{n}$ & \\
\hline 16 & at & prep & \\
\hline 17 & upon & prep & \\
\hline 18 & employee & $\mathrm{n}$ & \\
\hline 19 & charity & $\mathrm{n}$ & \\
\hline 20 & cottage & $\mathrm{n}$ & \\
\hline 21 & snow & $\mathrm{n}$ & \\
\hline 22 & cousin & $\mathrm{n}$ & \\
\hline 23 & uncle & $\mathrm{n}$ & \\
\hline 24 & review & $\mathrm{n}$ & \\
\hline 25 & bean & $\mathrm{n}$ & \\
\hline 26 & dairy & $\mathrm{n}$ & \\
\hline 27 & aunt & $\mathrm{n}$ & \\
\hline 28 & privacy & $\mathrm{n}$ & \\
\hline 29 & nephew & $\mathrm{n}$ & \\
\hline
\end{tabular}

Thank you for your help!

\section{Copyrights}

Copyright for this article is retained by the author(s), with first publication rights granted to the journal.

This is an open-access article distributed under the terms and conditions of the Creative Commons Attribution license (http://creativecommons.org/licenses/by/3.0/). 